\title{
Retraction of: Optimization of Suzhou Creek Rehabilitation Project Stage 1: Based on Water Quality Model, by Zuxin Xu and Zhenliang Liao. Environ Eng Sci 2006; 23(2):253-262. DOI: 10.1089/ees.2006.23.253
}

The PUblished article entitled, Optimization of Suzhou Creek Rehabilitation Project Stage 1: Based on Water Quality Model, by Zuxin Xu and Zhenliang Liao. Environ Eng Sci 2006; 23(2):253-262. DOI: 10.1089/ees.2006 .23 .253 is being officially retracted from Environmental Engineering Science due to duplicate publication.

One of the coauthors, Dr. Zhenliang Liao, contacted the Editor of Environmental Engineering Science on October 29, 2018 to report that their work had been previously published in the International Water Association (IWA) journal, Water Science and Technology in November of 2005.

Dr. Liao stated that the "paper was first submitted to the $4^{\text {th }}$ World Water Congress of the International Water Association, Marrakesh, Morocco, September 19-24," and that, "there was no response from IWA for a long time after the conference. Thus, [we] believed that IWA would not publish it. Then, [we] rewrote it and submitted it to Environmental Engineering Science." Dr. Liao's communication continues by saying, "However, I found that the original version of the paper was published by Water Science and Technology of IWA ...2005, 52(9):69-75."

Dr. Liao willingly brought this discovery to the Editor of EES and stated that the duplicate submission was unintentional and issued an apology. He stated that he was unaware that Water Science and Technology had published the paper as he had not been notified of its acceptance.

Environmental Engineering Science is committed to upholding the proper protocols and best practices of scientific publishing and in keeping with these guidelines, is officially retracting the article from the literature. The editorial leadership of Environmental Engineering Science has also reported this incident to the editors of the IWA journal, Water Science and Technology. 